\title{
ANALISIS PERTUMBUHAN DAN HASIL TANAMAN SUNGKAI (Peronema canescens Jack.) DI KALIMANTAN
}

\author{
Wahyudi ${ }^{1)}$, Zainal Muttaqin ${ }^{2)}$ dan A. Russel Mojiol ${ }^{3)}$ \\ ${ }^{1}$ Jurusan Kehutanan, Fakultas Pertanian, Universitas Palangka Raya \\ Palangka Raya, Indonesia (isanautama@yahoo.com) \\ ${ }^{2}$ Fakultas Kehutanan, Universitas Nusa Bangsa, Bogor, Indonesia (znldeg@yahoo.com) \\ ${ }^{3}$ School of International Tropical Forestry, University of Malaysia, Sabah, Malaysia \\ (rmojiol@yahoo.co.uk)
}

\section{ABSTRACT \\ Growth and Yield Analysis of Peronema canescens Jack. in Kalimantan}

\begin{abstract}
Sungkai (Peronema canescens) is a native and local species and one of some commercial trees which has a good prospect to be developed in timber estate in Kalimantan.This research was aimed to analyse sungkai plantation, neither the living percentage, productivity, economic cutting cycle, and also its profit. The data analysis was using the average of trees diameter, high and volume, mean annual increment, polynomial equation modelling and financial analysis i.e. net present value (NPV), benefit cost ratio (BCR) and internal rate of return (IRR). The research had been conducted at the community plantation in Kapuas District, Central Kalimantan Province since 1998 to 2010. The result of this research showed that living trees precentage at 12 years old was $89.7 \%$, mean annual increment and its density were $10,14 \mathrm{~m}^{3} \mathrm{ha}^{-1}$ and 997 tree/ha respectively. Equation modelling of sungkai plantation was $y=2,073+1,6623 x-0,0165 x^{2}\left(R^{2}=84,05 \%\right)$. In the bank rate of $9 \%$ per year, the economic cutting cycle of this plantation was 15 years with net present value was NPV 58,49 million per ha. BCR 7,64 and IRR 11,75 If the bank rate of 6\% and 12\% per year, then net present value at the 15 years were NPV 92.65 and 36.6 million per ha respectively. The sangtein was suitable as timber estate and to increase the productivity of former shifting cultivation, scru, and low potential forests which were widespread, especially in Kalimantan.
\end{abstract}

Keywords : Growth and yield, mean annual increment, Peronema canescens, economic cutting cycle

\begin{abstract}
ABSTRAK
Sungkai adalah jenis tanaman komersial lokal dan asli yang mempunyai prospek baik untuk dikembangkan dalam hutan tanaman Kalimantan. Penelitian ini bertujuan untuk mengetahui prosen hidup, produktivitas, siklus tebang optimum, dan keuntungan finansial dari tanaman sungkai. Penelitian dilakukan di hutan tanaman rakyat, Kabupaten Kapuas Provinsi Kalimantan Tengah. Obyek penelitian ialah tanaman sungkai yang ditanam sejak tahun 1998 pada tipe tanah Ultisol. Analisis data menggunakan nilai rataan diameter, tinggi dan volume, riap tahunan rata-rata tahunan, persamaan regresi, NPV, BCR dan IRR. Hasil penelitian menunjukkan bahwa pada umur 12 tahun prosen hidup tanaman mencapai 89,7 \%, riap tahunan rata-rata 10,14 $\mathrm{m}^{3} \mathrm{ha}^{-1}$ year $^{-1}$ dengan kerapatan 997 pohon/ha. Model pertumbuhan tanaman sungkai ialah $\mathrm{y}=2,073+1,6623 \mathrm{x}-$ $0,0165 \mathrm{x}^{2}\left(\mathrm{R}^{2}=84,05 \%\right)$. Pada tingkat suku bunga pinjaman $9 \%$ per tahun, tanaman sungkai mempunyai siklus tebang ekonomi selama 15 tahun dengan nilai NPV Rp. 58,49 juta/ha, BCR: 7,64 dan IRR: 11,75\%. Pada tingkat suku bunga pinjaman $6 \%$ dan $12 \%$ per tahun, maka pada siklus tebang selama 15 tahun, nilai NPVnya masing masing menjadi Rp. 92,65 juta/ha dan Rp. 36,6 juta/ha. Tanaman sungkai sangat sesuai dikembangkan dalam hutan tanaman dan untuk meningkatkan produktivitas lahan bekas perladangan berpindah, semak belukar dan hutan potensi rendah yang tersebar luas, khususnya di Kalimantan.
\end{abstract}

Kata kunci : Pertumbuhan dan hasil, riap tahunan rata - rata, Peronema canescens, siklus tebang ekonomi 


\section{PENDAHULUAN}

Luas kawasan hutan di Indonesia selalu mengalami penurunan. Pada tahun 70-an, luas kawasan hutan Indonesia adalah 164 juta ha (Suratmo et al. 2003), kemudian menurun menjadi 144 juta ha pada tahun 1981 (Hani'in 1999) dan menurun kembali menjadi 136,56 juta ha (Ditjen BUK 2010). Dalam kawasan hutan tersebut, luas areal yang berhutan hanya sebesar $64 \%$ dan areal non hutan 29\% (Balitbanghut 2008).

Laju kerusakan hutan sebesar 1,8 juta ha per tahun (1985 - 1997) dan meningkat menjadi 2,84 juta ha per tahun pada tahun 1997-2000 (Balitbanghut 2008). Sejalan dengan penurunan luas kawasan hutan serta tingginya laju kerusakann hutan, kemampuan produksi kayu bulat nasional juga mengalami penurunan. Pada tahun 1992 produksi kayu bulat nasional sebesar 26,05 juta $\mathrm{m}^{3} /$ tahun, namun kemudian menurun tajam pada tahun 2001 menjadi hanya 1,81 juta $\mathrm{m}^{3} /$ tahun. Sejak saat itu produksi kayu bulat nasional tidak pernah mencapai angka di atas 10 juta $\mathrm{m}^{3} /$ tahun.

Untuk meningkatkan kembali produksi kayu bulat nasional dapat ditempuh melalui pembangunan hutan tanaman, baik yang dilakukan oleh perusahaan dalam bentuk izin Usaha Pemanfaatan Hasil Hutan Kayu-Hutan Tanaman (IUPHHK-HT) maupun dilakukan oleh masyarakat dalam bentuk Hutan Tanaman Rakyat (HTR), Hutan Rakyat dan lain-lain. Pemilihan jenis tanaman merupakan komponen penting untuk menunjang keberhasilan program hutan tanaman. Jenis-jenis intoleran yang dapat tumbuh di daerah terbuka merupakan pilihan yang tepat untuk dikembangkan dalam kawasan hutan yang telah terdegradasi.

Salah satu jenis komersial lokal (native species) yang dapat dikembangkan dalam hutan tanaman adalah sungkai (Peronema canescens Jack.). Menurut Dephut (1989), kayu sungkai mempunyai berat jenis rata-rata 0,63 ; kelas awet III dan kelas kuat II-III. Kayu ini sangat sesuai digunakan untuk bahan bangunan, furniture, meubel, papan, lantai, dinding, patung dan ukiran, kerajinan tangan dan vinir. Kayu sungkai dikenal mempunyai warna yang cerah dan serat yang indah. Daun sungkai juga dapat digunakan sebagai obat sakit gigi dan menurunkan demam panas (Ditjenhut 1980).

Dalam rangka mendukung pengembangan hutan tanaman kelas perusahaan kayu sungkai, khususnya di Kalimantan, maka diperlukan informasi tentang pertumbuhan dan hasil serta analisis kelayakan finansial terhadap tanaman ini. Oleh karena itu penelitian tentang tanaman sungkai ini sangat diperlukan.

Penelitian ini bertujuan untuk mengetahui prosen hidup, produktifitas, siklus tebang ekonomi dan keuntungan finansial dari tanaman sungkai. Informasi ini diharapkan dapat membantu para pihak (stakeholder) dalam membangun hutan tanaman menggunakan jenis sungkai.

\section{METODE PENELITIAN}

\section{Tempat dan Waktu}

Penelitian dilakukan di hutan tanaman rakyat yang terletak di Kecamatan Mandau Talawang, Kabupaten Kapuas, Provinsi Kalimantan Tengah. Pengambilan data dilakukan setiap 3 tahun sejak penanaman tahun 1998 sampai tahun 2010.

\section{Prosedur Penelitian}

1. Plot penelitian berada dalam hutan tanaman rakyat jenis sungkai (Peronema canescens Jack.) yang ditanam tahun 1998 dengan jarak tanam $3 \mathrm{~m} \times 3 \mathrm{~m}$. Plot penelitian merupakan semak belukar dan hutan potensi rendah serta bekas perladangan berpindah. Jenis tanah Ultisol berwarna kuning kemerahan dengan tekstur lempung liat berpasir (sandy clay loam). Tebal lapisan humus berkisar $0,5 \mathrm{~cm}$ sampai $21 \mathrm{~cm}$.

2. Plot penelitian ditentukan seluas 1 ha yang diambil secara acak.

3. Pengambilan data dilakukan terhadap diameter (dbh) dan tinggi bebas 
cabang pada tahun 2001, 2004, 2007, 2010 .

\section{Analisis Data}

1. Rata - rata data ditentukan menggunakan rumus :

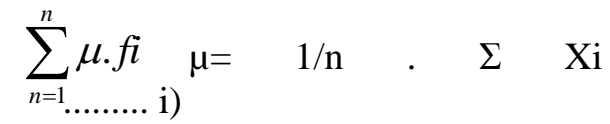

Dimana :

$\Sigma \mathrm{Xi}=$ jumlah data dari $\mathrm{X}_{1}$ sampai $\mathrm{X}_{\mathrm{n}}$

$\mu \quad=$ nilai tengah atau rata - rata

$\mathrm{n} \quad=$ banyak data

2. Prosentase hidup tanaman ditentukan menggunakan pendekatan :

Prosen hidup $=(\Sigma$ tanaman hidup $/$ $\Sigma$ tanaman yang ditanam) X $100 \%$ ..ii)

3. Volume pohon dihitung melalui :

$\left.\mathrm{V}=0,25 \cdot \Pi \cdot \mathrm{D}^{2} \cdot \mathrm{h} \cdot 0,7 \quad \ldots . . \mathrm{iii}\right)$

dimana :

$\Pi=3,14 ;$

$\mathrm{D}=$ diameter $\mathrm{dbh}$

$\mathrm{h}=$ tinggi pohon.

4. Pola pertumbuhan tanaman sungkai dibentuk melalui persamaan polinomial (Brown, 1997; Burkhart, 2003)

$\left.\mathrm{y}=\mathrm{c}_{1}+\mathrm{c}_{2} \mathrm{x}+\mathrm{c}_{3} \mathrm{x}^{2} \quad \ldots . \mathrm{iv}\right)$

dimana :

y : diameter akhir rata - rata

$\mathrm{x} \quad$ : waktu dalam tahun

$\mathrm{c}_{1}, \mathrm{c}_{2}, \mathrm{c}_{3}$ : konstanta

\section{Analisa Finansial}

Perhitungan Net Present Value (NPV), Benefit Cost Ratio (BCR dan
Internal Rate of Return (IRR) ditentukan melalui persamaan (Nair, 1993):

$$
\begin{aligned}
& \mathrm{NPV}=\sum_{\mathrm{t}=0}^{\mathrm{r}} \frac{\mathrm{B}_{\mathrm{i}}}{(1+\mathrm{i})^{\mathrm{t}}}-\sum \underset{\mathrm{t}=0 \quad(1+\mathrm{i})^{\mathrm{t}}}{\mathrm{r}} \mathrm{C}_{\mathrm{i}} \\
& \mathrm{BCR}=\sum_{\mathrm{t}=0}^{\mathrm{r}} \frac{\mathrm{B}_{\mathrm{i}}}{(1+\mathrm{i})^{\mathrm{t}}}: \sum_{\mathrm{t}=0 \quad(1+\mathrm{i})^{\mathrm{t}}}^{\mathrm{r}}
\end{aligned}
$$

Internal Rate of Return (IRR) adalah nilai suku bunga (i) pada saat NPV $=0$

$\mathrm{NPV}=\sum_{\mathrm{t}=0}^{\mathrm{n}} \frac{\mathrm{Bt}-\mathrm{Ct}}{(1+\mathrm{i})^{\mathrm{t}}}=0$

dimana :

$\mathrm{Bt} \quad$ : penerimaan (benefit) tahun ke-t

$\mathrm{Ct}$ : pengeluaran (cost) tahun ke-t

$\mathrm{r}, \mathrm{t}$ dan $\mathrm{i}$ : siklus tebang, waktu (tahun) dan suku bunga

Proyek dinilai layak bila NPV $>0$, BCR $\geq 1$ dan IRR > suku bunga.

Analisis sensitifitas dilakukan untuk mengetahui output proyek jika terdapat suatu penyimpangan atau perubahan dalam dasar-dasar perhitungan biaya (cost) maupun manfaat (benefit) (Gray et al. 1999). Dalam penelitian ini analisis sensitifitas dilakukan terhadap beberapa tingkat suku bunga, yaitu $6 \%$ dan $12 \%$.

\section{HASIL DAN PEMBAHASAN}

Tanaman sungkai (Peronema canescens) pada umur 12 tahun mempunyai riap diameter tahunan rata rata (MAI diameter) sebesar $1,72 \mathrm{~cm} /$ tahun dan riap tinggi bebas cabang tahunan rata rata (MAI tinggi bc) sebesar $0,62 \mathrm{~m} /$ tahun. Hasil pengukuran diamater dan tinggi bebas cabang tanaman sungkai dapat dilhat 
pada Tabel 1. Menurut Ditjenhut (1980) tanamn sungkai yang ditanam di Gadungan dengan jarak tanam $3 \mathrm{~m} \times 1 \mathrm{~m}$ mempunyai MAI diameter sebesar $1,02 \mathrm{~cm} /$ tahun. Dengan demikian tanaman sungkai di lokasi penelitian ini mempunyai riap tahunan rata-rata yang lebih besar dibanding di daerah Gadungan.

Prosentase hidup tanaman sungkai pada umur 12 tahun sebesar $89,71 \%$. Tanaman sungkai merupakan jenis asli Kalimantan yang relatif tahan pada kondisi tanah marginal, sehingga tidak banyak ditemukan angka kematian pohon tiap tahunnya. Beberapa tanaman ada yang terserang hama kumbang moncong (Alcides sp) yang menyebabkan daun berlubang-lubang, namun tidak sampai membuat tanaman mati. Secara umum, penurunan prosentase hidup tanaman disebabkan adanya persaingan dalam memperoleh unsur - unsur hara dalam tanah dan ruang tumbuh.

Pola pertumbuhan tanaman sungkai membentuk persamaan polinomial (Brown, 1997; Burkhart, 2003) sebagai berikut :

$\mathrm{y}=2,073+1,6623 \mathrm{x}-0,0165 \mathrm{x}^{2}$

$\left(\mathrm{R}^{2}=84,05 \%\right)$

Di mana :

$\mathrm{y}:$ diameter akhir rata - rata

$\mathrm{x}$ : waktu dalam tahun

Tabel 1. Riap Diameter dan Tinggi Bebas Cabang Tanaman Sungkai sampai Umur 12 tahun

\begin{tabular}{ccccccc}
\hline Tahun & Umur & $\begin{array}{c}\text { Diameter } \\
(\mathrm{cm})\end{array}$ & $\begin{array}{c}\text { MAl diameter } \\
(\mathrm{cm} / \mathrm{th})\end{array}$ & $\begin{array}{c}\text { Tinggi bebas } \\
\text { cabang }(\mathrm{m})\end{array}$ & $\begin{array}{c}\text { MAl Tbc } \\
(\mathrm{m} / \mathrm{th})\end{array}$ & Ket \\
\hline 1998 & 0 & 1,86 & 0,00 & 0,3 & 0,00 \\
2001 & 3 & 7,39 & 2,46 & 2,2 & 0,73 & \\
2004 & 6 & 15,80 & 2,63 & 3,8 & 0,63 \\
2007 & 9 & 17,65 & 1,96 & 5,2 & 0,58 \\
2010 & 12 & 20,58 & 1,72 & 7,4 & 0,62 & \\
\hline
\end{tabular}

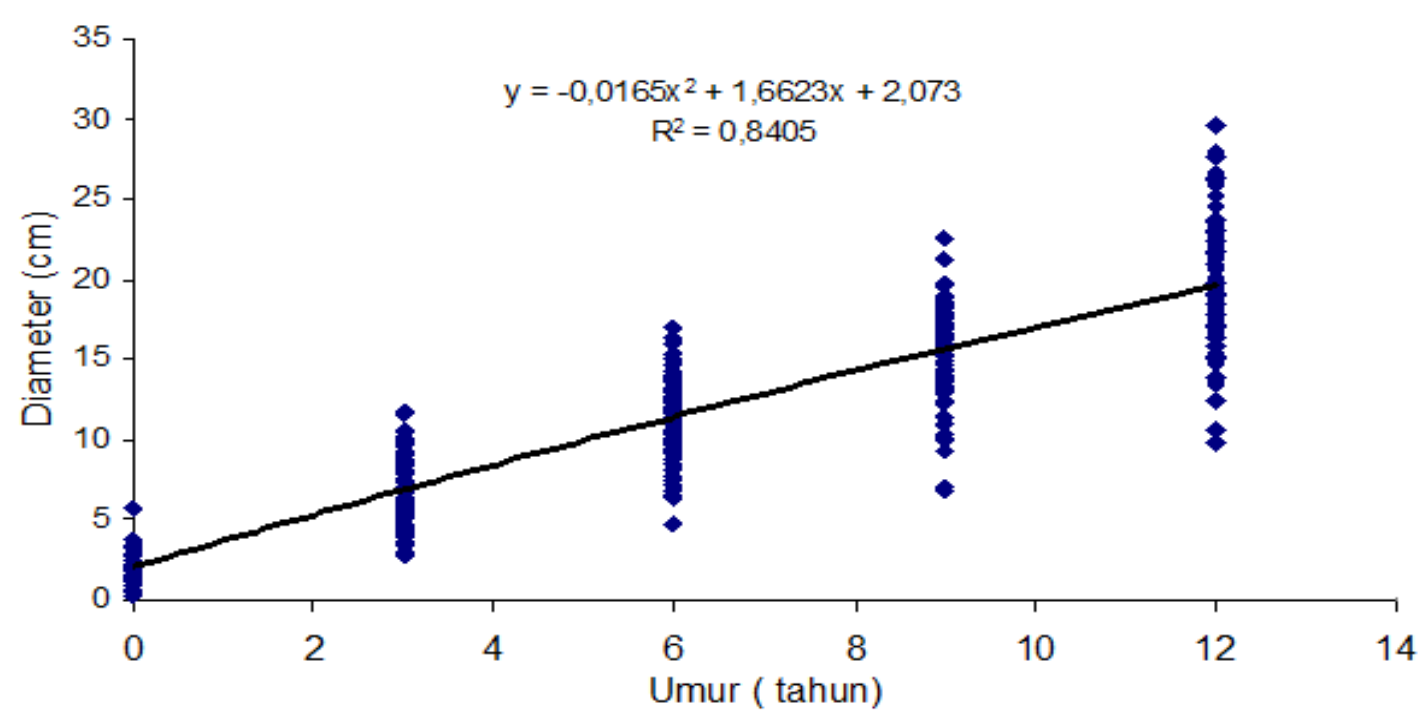

Gambar 1. Model Persamaan Polinomial pada Pertumbuhan Tanaman Sungkai 
Berdasarkan model persamaan di atas, dapat diprediksi besaran diameter dan tinggi bebas cabang ke depan, demikian pula dengan volumenya. Berdasarkan pendekatan tersebut, MAI volume total tanaman sungkai pada penelitian ini sebesar 10,14 $\mathrm{m}^{3} / \mathrm{ha} /$ tahun dengan kerapatan 997 pohon/ ha pada umur 12 tahun. Menurut Ditjenhut (1980) tanamn sungkai yang ditanam di Gadungan dengan jarak tanam $3 \mathrm{~m}$ x $1 \mathrm{~m}$ mempunyai MAI volume total $11,5 \mathrm{~m} 3 / \mathrm{ha} /$ tahun. Dengan demikian tanaman sungkai di lokasi penelitian ini mempunyai riap tahunan rata - rata yang lebih kecil dibanding di daerah Gadungan.

MAI diameter pada penelitian ini lebih besar dari MAI diameter di Gadungan, namun MAI volumenya lebih kecil. Hal ini disebabkan prosentase hidup tanaman sungkai di lokasi penelitian ini lebih kecil di banding prosentase hidup tanaman sungkai di daerah Gadungan. Pada penelitian ini prosentase hidup tanaman sungkai sebesar $89,71 \%$ dengan kerapatan tanaman 997 pohon/ha pada umur 12 tahun. Jumlah tanaman sungkai pada awalnya penanaman sebesar 1.111 pohon/ha.

Analisis finansial tanaman sungkai dilakukan dengan memprediksi pencapaian volume tanaman sungkai per ha sampai umur 35 tahun. Dengan menggunakan asumsi harga jual kayu sungkai berdiameter 10-20 sebesar Rp. 850.000,per $\mathrm{m}^{3}$ dan berdiameter $20 \mathrm{~cm}$ ke atas sebesar Rp. 1.500.000,- per $\mathrm{m}^{3}$, maka dengan tingkat suku bunga 9\% (berlaku saat ini), siklus tebang ekonomis dicapai pada umur 15 tahun dengan nilai NPV sebesar Rp. 58,49 juta/ha, BCR sebesar 7,64 dan IRR 11,75\% (Tabel 2). Apabila tingkat suku bunga turun menjadi 6\%, maka siklus tebang ekonomis dicapai pada umur 15 tahun dengan nilai NPV sebesar Rp. 92,65 juta/ha, BCR sebesar 10,62 dan IRR $11,79 \%$ dan apabila tingkat suku bunga naik menjadi $12 \%$, maka siklus tebang ekonomis dicapai pada umur 15 tahun dengan nilai NPV sebesar Rp. 36,6 juta/ha, BCR sebesar 5,47 dan IRR 11,66\% (Tabel 2).

Berdasarkan data pada Tabel 2, tanaman sungkai telah layak dipanen pada umur 10 tahun namun belum memberi keuntungan finansial maksimal. Apabila tanaman dipanen pada umur lebih dari 15 tahun, maka tidak diperoleh keuntungan yang maksimal karena beban biaya perawatan tanaman serta beban suku bunga yang dikenakan pada tiap komponen pengeluaran lebih tinggi dibanding penambahan keuntungan dari riap tanaman.

Menurut Sutisna dan Ruchaemi (1995), tanaman sungkai dapat dipanen sebagai kayu perkakas pada umur $20-30$ tahun. Berdasarkan hasil penelitian ini, tanaman sungkai masih layak dipanen pada umur $20-30$ tahun juga, namun berdasarkan kondisi saat ini, dimana teknologi pengolahan kayu telah berkembang pesat dan kayu sungkai berdiameter $10-20 \mathrm{~cm}$ telah bernilai ekonomis, maka pemanen pada umur 15 tahun adalah yang paling layak dengan keuntungan finansial tertinggi. Penundaan pemanenan akan menambah biaya proyek dan kurang efisien.

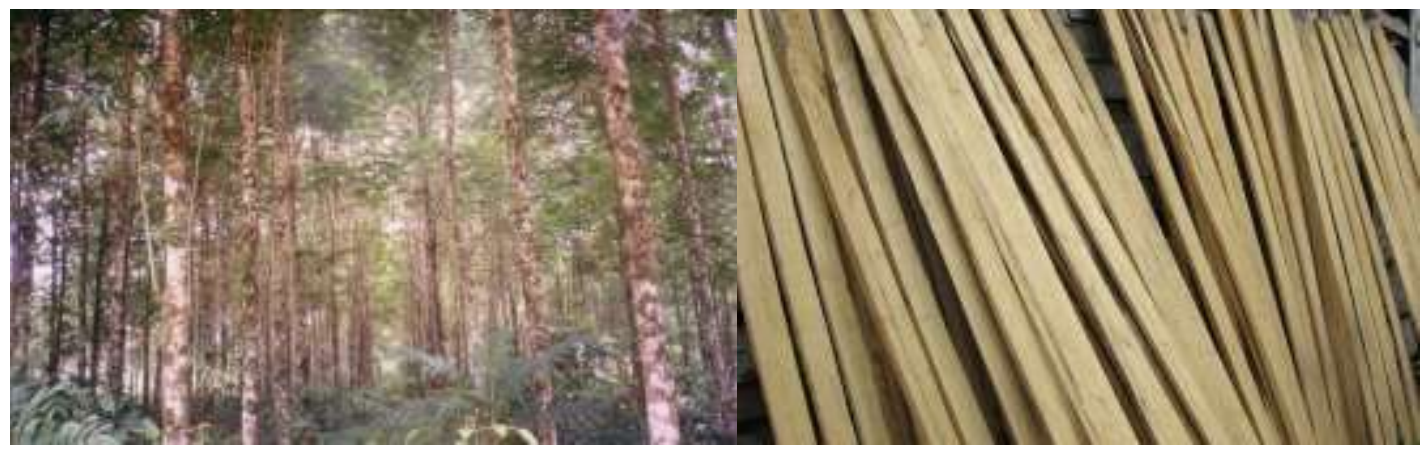

Gambar 2. Tanaman Sungkai Umur 12 Tahun (Kiri) dan Papan Sungkai (Kanan) 
Tabel 2. Analisis Finansial Tanaman Sungkai pada Tingkat Suku Bunga 9\%, 6\% dan 12\%

\begin{tabular}{|c|c|c|c|c|}
\hline suku bunga & Umur & NVP & $\mathrm{BCR}$ & IRR \\
\hline \multirow{7}{*}{$9 \%$} & 5 & -6.722 .000 & 0,00 & $8,3 \%$ \\
\hline & 10 & $10,381,813$ & 2,29 & $11,87 \%$ \\
\hline & 15 & 58.489 .927 & 7,64 & $11,75 \%$ \\
\hline & 20 & $46,399,275$ & 5,96 & $10,86 \%$ \\
\hline & 25 & 38.299 .379 & 4,95 & $10,34 \%$ \\
\hline & 30 & 25.426 .666 & 3,53 & $10,06 \%$ \\
\hline & 35 & 19.451 .165 & 2,92 & $9,89 \%$ \\
\hline \multirow{7}{*}{$6 \%$} & 5 & -6.083 .933 & 0,00 & $8,31 \%$ \\
\hline & 10 & 15.020 .010 & 2,07 & $12,21 \%$ \\
\hline & 15 & 92.651 .088 & 10,62 & $11,79 \%$ \\
\hline & 20 & $86,899,446$ & 9,26 & $10,95 \%$ \\
\hline & 25 & 85.247 .273 & 8,63 & $10,46 \%$ \\
\hline & 30 & 82.229 .511 & 7,83 & $10,04 \%$ \\
\hline & 35 & 78.111 .598 & 7,35 & $9,87 \%$ \\
\hline \multirow{7}{*}{$12 \%$} & 5 & -6.580 .139 & 0,00 & $8,31 \%$ \\
\hline & $1 \pi$ & ศ. З98.П२К & 1,84 & $11,34 \%$ \\
\hline & 15 & 36.601 .192 & 5,17 & $11,66 \%$ \\
\hline & 20 & 23.072 .147 & 0,00 & $10,67 \%$ \\
\hline & 25 & 15.642 .235 & 2,79 & $10,04 \%$ \\
\hline & 30 & $4,855,190$ & 1,55 & $10,06 \%$ \\
\hline & 35 & 1.094 .425 & 1,12 & $9,92 \%$ \\
\hline
\end{tabular}

\section{KESIMPULAN}

Sungkai (Peronema canescens jack.) adalah jenis komersial asli Kalimantan yang bersifat intoleran dan dapat tumbuh dengan baik pada areal bekas perladangan, semak belukar dan hutan rawang yang tersebar luas dalam kawasan hutan. Pada umur 12 tahun prosen hidup tanaman sungkai mencapai $89,7 \%$, riap tahunan rata-rata $11,90 \mathrm{~m}^{3} \mathrm{ha}^{-1}$ year $^{-1}$ dengan kerapatan 997 pohon /ha. Model pertumbuhan tanaman sungkai adalah $\mathrm{y}=2,073+1,6623 \mathrm{x}-0,0165 \mathrm{x}^{2}$ $\left(\mathrm{R}^{2}=84,05 \%\right)$. Pada tingkat suku bunga pinjaman $9 \%$ per tahun, tanaman sungkai mempunyai siklus tebang ekonomis selama 15 tahun dengan nilai NPV Rp. 58,49 juta/ha, BCR : 7,64 dan IRR : 11,75\%. Apabila tingkat suku bunga pinjaman turun menjadi $6 \%$ atau naik menjadi $12 \%$ per tahun, maka siklus tebang ekonomis masih tercapai pada umur 15 tahun dengan nilai NPV-nya masing-masing sebesar Rp. 92,65 juta/ha dan Rp. 36,6 juta/ha. Tanaman sungkai dapat dipergunakan untuk kegiatan reboisasi dan penghijauan dalam rangka meningkatkan produktifitas lahan serta layak dikembangkan dalam hutan tanaman industri kelas perusahaan kayu pertukangan dalam skala luas karena permintaan kayunya yang semakin meningkat.

\section{DAFTAR PUSTAKA}

[Balitbanghut] Badan Penelitian dan Pengembangan Kehutanan. 2008. Profil Pusat Penelitian dan Pengembangan Hutan dan Konservasi Alam. Balitbanghut, Departemen Kehutanan, Bogor. 
Brown S., 1997. Estimating biomass change of tropical forest a primer. FAO Forestry Paper No.134. FAO USA.

Burkhart HE., 2003. Suggestion for choosing an appropriate level for modelling forest stand. In Amaro A, Reed D, Soares P, editors. Modelling Forest System. CABI Publishing.

Dephut] Departemen Kehutanan RI, 1989. Atlas Kayu Indonesia. Jilid I dan II. Badan Litbang Dephut, Bogor.

[Ditjenhut] Direktorat Jenderal Kehutanan, 1980. Pedoman Pembuatan Tanaman. Direktorat Jenderal Kehutanan, Departemen Pertanian, Jakarta.

[Ditjen BUK] Direktorat Jenderal Bina Usaha Kehutanan, 2010. Kebijakan dan Strategi Pengelolaan Hutan Produksi. Ditjen BUK Departemen Kehutanan, Jakarta.

Gray C, Kadariah L, Karlina, 1999. Pengantar Evaluasi Proyek. Edisi Revisi. Lembaga Penerbit Fakultas Ekonomi Universitas Indonesia, Jakarta.
Hani'in O., 1999. Pemuliaan pohon hutan Indonesia menghadapi tantangan abad 21. Dalam Hardiyanto EB, editor. Prosiding Seminar Nasional Status Silvikultur 1999. Peluang dan Tantangan Menuju Produktifitas dan Kelestarian Sumberdaya Hutan Jangka Panjang. Wanagama I. Fakultas Kehutanan UGM, Yogyakarta.

Hatta, G. M., 1999. Sungkai (Peronema canescens). A Promising Pioneer Tree : An Experimental Provenance Study in Indonesia. Wageningen Universiteit, Netherland.

Nair PKR., 1993. An Introduction to Agroforestry. Kluwer Academic Publishers. ICRAF. DordrechtBoston-London.

Suratmo FG, Husaeni EA and NS. Jaya 2003. Pengetahuan Dasar Pengendalian Kebakaran Hutan. Fakultas Kehutanan IPB, Bogor.

Sutisna, M. dan Ruchaemi, 1995. Hutan Tanaman di Kalimantan Timur. Direktorat Jenderal Pengusahaan Hutan, Dephut RI, Jakarta. 